\title{
ON THE POSITION OF CHAMAEA IN THE SYSTEM.
}

R. W. SHUFELDT.

There are two species of Chamea in the United States avifauna, - the $C$. fasciata, which is confined to the coast region of California, and C.f. henshawei, a variety of the latter which ranges through the "interior of California, including the western slope of the Sierra Nevada." Ornithologists have bestowed the name of the Wren-Tit upon the first-mentioned of these, while the second one is referred to as the Pallid Wren-Tit. In the absence of any detailed and published account of the structure of Chamaa, made comparative with its supposed affines, one would naturally be led to believe, from these names, that the systematists regard these birds as Tits with a tincture of Wren in them; and such, I understand, is generally the case, or otherwise they would certainly have been designated as Tit-Wrens. Several dissenters from this opinion are, however, known to me, and chief among these I would allude to Mr. Robert Ridgway, Mr. F. A. Lucas, and Mr. J. A. Allen. In conversation with Mr. Ridgway on the subject, although he seemed to be disinclined to advance any decided opinion in the premises, he left the impression upon my mind that he regarded Chamcea more as a Wren than a Tit, and very kindly allowed me to examine skins of both groups in the collections of the Smithsonian Institution. Among these he was so good as to point out and invite my attention to the external characters in such forms as Cinnicerthia unibrunnea and Cinnicerthia unimufa, the first being a species from Ecuador, and the latter from Colombia. He remarked that, in his opinion, these birds were Wrens, and I was struck with their general external resemblance to Chamaa, more especially in the case of unimufa, which, if I remember, was the species with the longer tail. Both, however, were, upon the whole, unitinted; their heads tufti-crested; a tendency in one for the tarsal scutella to become obsolete; and in the case with 
both, the form, size, bill, and general facies were considerably like Chamcea. It was also interesting to note that these birds had the flight-feathers of the wings indistinctly barred, as we so often find them among certain troglodytine types.

Mr. Lucas has published it as his opinion "that Chamea appears most decidedly to belong with the Wrens, and not with the Titmice." (Proc. U. S. Nat. Mus., 1888, p. 180.) Finally, Mr. J. A. Allen, in a letter to the writer under date of June I4, I889, says, "I know of no South American forms near Chamea, outside of the Wrens, of which South America furnishes a large and varied assortment."

With these facts before us, it would seem that a careful comparative study of the structure of Chamaa could be nothing less than a well-chosen task, and one decidedly worthy of the labor required to complete it. It is such a work that I have to present in the present paper, and I am indebted to a number of my friends for material wherewith to prosecute it. Chief among these it gives me pleasure to thank Mr. F. Stephens, of Ballena, California, for upwards of a dozen specimens of Chamea fasciata henshawei, and adult and young of Thryothorus b. spilutrus; this material was collected for me by Mr. Stephens, and generously donated by Mr. G. Frean Morcum, of Chicago. They were all alcoholics. Ten or twelve years ago I also received a good skeleton of Chamea fasciata from Mr. C. A. Allen, of Nicasio, California, and my thanks are due to the same naturalist for a specimen of Parus rufescens in alcohol. Mr. Herbert Brown, of Tucson, Arizona, sent me a series of beautiful specimens of Auriparus faviceps and Campylorhynchus brunncicapillus, which yielded some excellent skeletons, for which I was especially grateful. My valued friend, Professor Alfred Newton, F.R.S., of Cambridge, England, generously sent me alcoholics of adult $\delta$ and $\$$, and juv. of Accentor modularis, which were suggested by him to be compared in the same connection. It was also through Professor Newton's kindness that I obtained from his friend, Lieutenant W. Wilfrid Cordeaux, of the 2d Dragoon Guards (Queen's Bays), some fine alcoholic specimens of the Paridee of the Northwestern Himalayas. Still later I was favored by Dr. George Bird Grinnell with a specimen of Pcrisoreus canadensis capitalis, with which I intended to make some comparisons of the skeleton between it and representatives of the sub-genus 
Lophophanes among the Titmice. Lieutenant Cordeaux kindly made the collection especially for the present work in the region indicated, and Dr. Leonard Stejneger did me the service of identifying the specimens after they came into my hands. Dr. Grinnell secured the Jay, to which I have just alluded, in Wyoming, and my thanks are due him for his thoughtfulness in the matter. Finally, I am much indebted to Mr. H. K. Coale, of Chicago, for numerous alcoholic specimens of North American Tits and Wrens sent me at different times to be used in the present memoir. My own collection affords either alcoholic specimens or skeletal preparations of an extended variety of our United States Paride, Certhiide, Cinclide, Troglodytide, and Mniotiltida, which I have collected during the past fifteen years in widely separated parts of the country.

From the material at hand it will be seen, then, that the principal forms that we lack for comparison are the various species of Wrens of the South American avifauna spoken of by Mr. Allen in his letter, and no one can regret more than the writer the absence for such a purpose of such species as are to be found in the genus Cinnicerthia, to which we have already alluded. But as those birds have never as yet been carefully examined and compared structurally with the species to be thus dealt with in this paper, we are just as likely to find them to be Wren-like Tits, a little nearer the Wrens than Chamea, as anything I know anything about. In its topographical characters Cinnicerthia uninufa, to be sure, very much resembles Chamaa fasciata, indeed very much more so than do either one of them resemble any of our North American Wrens.

Not long ago Mr. Sharpe described a new species of Cinnicerthia, in the Catalogue of the British Museum, I think, that looks from the drawing still more Wren-like than the two species alluded to in the previous paragraph, it possessing a longer bill and being still more distinctly barred on the wings and tail. Dr. Sclater in his Nomenclator Avium Neotropicalium places the Cinnicerthia among the Wrens, and next before the genus Campylorhynchus; and a number of ornithologists are of the opinion that our genus Thryothorus is the most nearly related genus of Wrens to Cinnicerthia, - that is, in the United States avifauna.

Among the typical Tits, so far as I have examined them, we 
find no species that particularly resembles Chamea in its general appearance. A mounted specimen of the Bearded Tit, in the collections of the Smithsonian Institution, which was shown me by Mr. Robert Ridgway, has some external characters, both in general form and less so in color, that suggest to our mind an affinity with perhaps some such form as our Chamaa. Beyond it, I found no species that appeared to offer any clue.

However, as I said before, if we confine ourselves strictly to the United States avifauna in the comparisons we make with Chamea, I am strongly inclined to believe that in the entirety of its structure it will possess more parine rather than troglodytine characters in its organization. For instance, when we come to consider all the external characters of Chamea, its habits, its nest and eggs, its habitat, and other matters bearing upon its history as a species, - taking all these, I say, into careful consideration, and without any regard to its internal structure, and even setting aside for the present its pterylography, I see its nearest allies in the various species of Psaltriparus, and secondly, in some very few particulars, in the sub-genus Lophophanes among the Parida. In point of size and in the tufted feathers of the head it more nearly resembles the last-named; while in habit, and in its rounded wings and long, graduated tail, and other points, it comes closer to species in the first-mentioned genus. Its resemblance to such a species as Auriparas flaviceps is, of course, very slight, and incleed that somewhat highly colored little bird is the most un-Tit-like-looking Tit that has been allowed a place among our United States Parida.

In the subjoined TABLE I contrast a few of the characters, etc., which characterize the subject of this memoir and such other species and genera as Psaltripanus, Auriparus faviccps, Panis, Accentor, and Thryothoris. When Professor Newton sent me the specimens of Accentor modularis to compare with Chamaa, he was, I think, more especially impressed with the fact that both the birds laid blue eggs, and in both the habits are not altogether unlike. As our examinations into the structure of these forms progress, however, I am convinced that $A c$ centor will prove to be a form very much like some of our larger American Warblers, such as for instance Geothlypis macgillivrayi, or perhaps some other. I have examined, through the 
No. 3.]

POSITION OF CHAMEA.

\begin{tabular}{|c|c|c|c|c|c|c|}
\hline 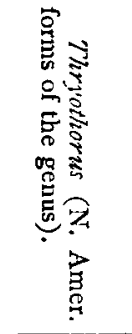 & 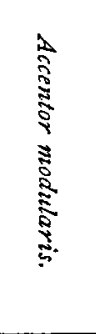 & 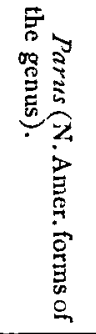 & 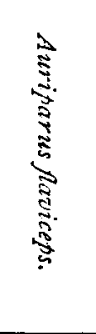 & 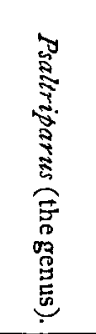 & 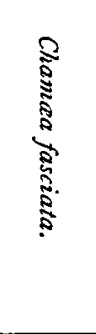 & 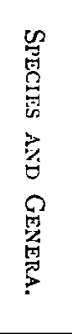 \\
\hline 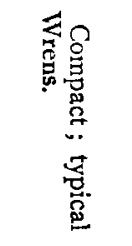 & 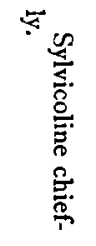 & 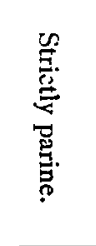 & 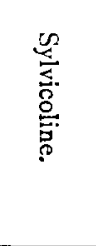 & 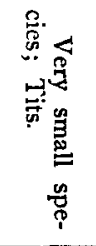 & 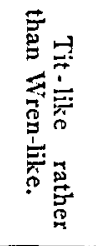 & 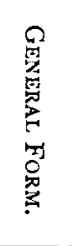 \\
\hline 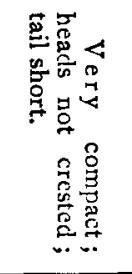 & 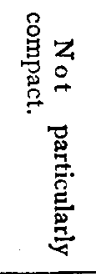 & 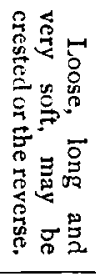 & 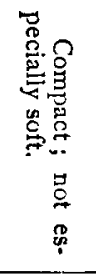 & 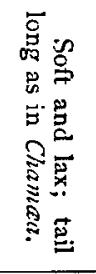 & 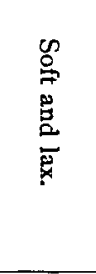 & 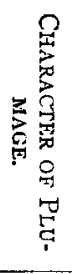 \\
\hline 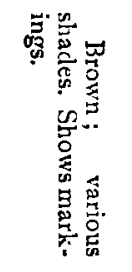 & 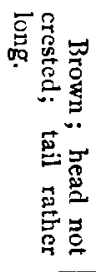 & 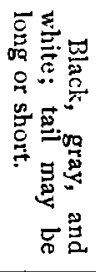 & 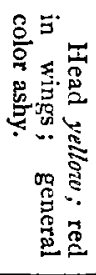 & 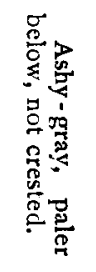 & 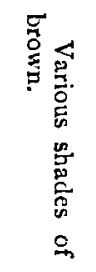 & 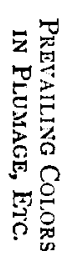 \\
\hline 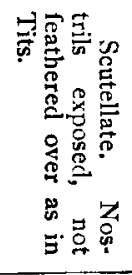 & 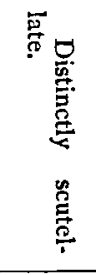 & 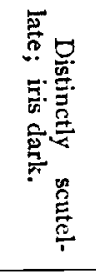 & 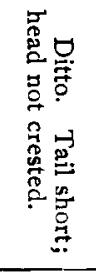 & 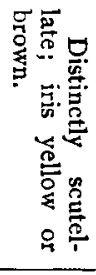 & 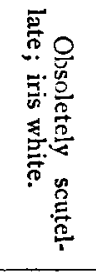 & 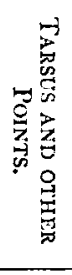 \\
\hline 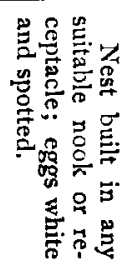 & 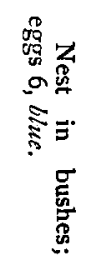 & 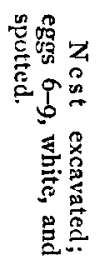 & 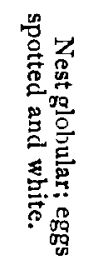 & 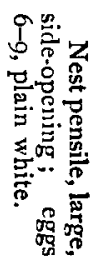 & 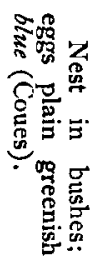 & 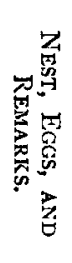 \\
\hline
\end{tabular}


courtesy of Mr. Ridgway, skins of both $A$. modularis and $A$. vulgaris, and this recent examination has in no way altered the opinion I expressed on this point a year or more ago ; indeed, it has in fact only strengthened it. So far as its topographical anatomy goes, $A$. modularis has all the appearance of a large ground Warbler; still, I intend to carry it along in our examinations in the present monograph, as it will widen the field and prove useful in other ways.

Of the Pterylography. - Upon plucking a specimen of Cha$m e a$, the ornithotomist is at once struck with the great length of the thighs and legs as compared with the size of the body of the bird. Further, it becomes evident that the pectoral limbs are relatively short, a short brachium, antibrachium, and pinion, and likewise this species has a short, thickset neck. As we would naturally expect, we find the pattern of the pterylographic areas to be passerine, with the "saddle tract" of the spinal pteryla to be rather small and distinctly lozenge-shaped. The continuation of this from its posterior angle to the uropygial (and untufted) gland is composed of almost a single line of feathers. The "ventral tracts" seem to present nothing peculiar.

After removing the plumage of a specimen of Parus inomatus griseus, it is seen to markedly differ in form from Chamea, being indeed in contour the perfect miniature of a Jay in this particular; and this species may remotely link the Paridee and the Corvida, perhaps through such a genus as Perisoreus. As to its pterylography, we find the "ventral tracts" considerably broader in proportion than they exist in Chamae, while the "saddle" of the spinal tract is more inclined to be rounded at its corners, though the same meagre line of feathers is continued from it below to the tail. There is a great deal to be learned by the careful study and comparison of the plucked bodies of birds, and similarity of form should be given its due weight. I was never more thoroughly impressed with this fact than when I for the first time compared the plucked bodies of a Swift and a Humming-bird. No two birds could be more thoroughly dissimilar than these in this important particular. Parus inornatus griseus has the "alar tracts" very densely feathered, and in this species there is an evident tendency for the tracts of the shoulders and neck to run together, - not so, however, in the subject of our paper. 
Serving a specimen of Psaltriparus plumbeus, as in the foregoing specimens, we at once recognize how very much it agrees in form with Chamea, and how it differs from Parus inornatus griseus. Once more we find the disproportionately long thighs and legs, with the short, thickset neck, though in Psaltriparus the pectoral limbs are relatively larger with respect to the size of the body than they are in Chamaa.

The pattern of the several pterylographical tracts are almost identically the same in these two genera.

With respect to form and pterylography the Chickadees, as represented by Parus gambcli, seem to offer the precise intermediates between Chamcea and P. i. griseus (Lophophanes), or between Psaltriparus and the latter. For in them we find a harmonious balance between limbs and body, though the pelvic pair are rather long. The neck is proportionately longer, and the head moderately smaller. Indeed, one might say in the body of this Chickadee there are really no proportional discrepancies, any more than there are in the form of the body in an average Sparrow. This mountain Chickadee likewise shows some departure in its pterylography, for the ventral tracts are much narrowed; the saddle of the spinal tract lozenge-shaped again, while quite a broad band of feathers, several rows at least, connect this latter with the dorsal caudal pteryla. All the Tits I have thus far plucked have the skin of the head, with the exception of that covering the throat, of a dark purplish hue; and $I$ am inclined to think that this is normal with them.

At some other time the writer has it in his mind to give the anatomy of the genus Sitta; and as there can be no very intimate affinity between it and Chamaa, we will not take it into consideration here. This should not debar us from taking a glance at such a form as Regulus satrafa, and I am under obligations to $\mathrm{Mr}$. H. K. Coale of Chicago for alcoholic specimens of this species. After one has been carefully plucked its diminutive body calls up to us Psaltriparus, but not so its form; for in Regulus we have the true sylvicoline contour, with its far more acutely conical head, the deep-set eyes, the justly proportioned limbs for the size of the body, which latter is robust, broad, showing evidences in front of the more prominent keel of the sternum.

Regulus has a large, lozenge-shaped saddle in its spinal tract; 
and this pteryla is quite broad, as it is continued on to the tail, the whole system of the pterylography causing the feathering to be quite dense in this species.

Both the form of the body and its pterylography in Regulus is substantially repeated in Polioptila plumbea, a specimen of which species I have this moment plucked, and now have before me. In it, however, there is an evident arrangement of the feathers in the capital area; for a strong, single, median row can be easily recognized, and another single row passes over each eye. The median row bifurcates anteriorly, the base of the culmen passing between the limbs, which latter have on either side the lateral orbital row merging into it. Judging from form of body and pterylography alone, I would hardly say there was any very close affinity between Chamea and the last two genera we have examined.

In the lot of alcoholics kindly collected for me by Mr. Coale, I also find an excellent specimen of Certhia familiaris americana; but aside from its curved and slender beak, the form of the body of this species is sylvicoline, with troglodytine affinities quite pronounced, while its pterylography is strictly passerine. From its topographical anatomy, and what we know of its habits, it surely has but a very slender kinship with Chamea.

The pterylography of Certhia familiaris has been correctly figured by Nitzsch. ${ }^{1}$

Passing next to one of our specimens of Accentor modularis, I find upon plucking it that its pterylography is very different from Chamea, having quite the same pattern which Nitzsch figures for Motacilla alba, ${ }^{2}$ though in Accentor the saddle tract of the dorsum is if anything proportionately larger, and the pteryla leading from it to the uropygial gland broad, and spreading posteriorly at its termination. All the pterylæ are clearly defined and strong in the Accentor.

The form of the body in this bird is what one might suppose to be as a cross between one of our average Sparrows and a large Warbler, say for instance, $D$. vigorsii $\times$ Ammodromus, at once noticeably different in contour from the subject of our paper. An arrangement of the feathers on the top of the head in this species are as I described them for Polioptila, with the exception

1 Pterylograpliy, Eng. ed. by Sclater, Taf. III., fig. 3.

2 Ibid., Taf. III., figs. I and 2. 
that the median band is much broader. And I wish it to be understood that in both species scattered feathers are to be found interspersed among the three longitudinal bands which I have attempted to describe. This condition is also pretty well seen in Chamae. There is but one other species we will examine just at present, so far as its topographical anatomy goes; and I propose to allow Salpinctes obsoletus to represent the Wrens, it being a good-sized Western form. In it we find a pterylography which approaches Certhia more nearly than any other species we have investigated, while in the form of its plucked body, it widely departs from Chamea, as its head is conspicuously large for its size; the neck rather long; the body or trunk very wide and compressed dorso-ventrally; the pectoral limbs long and powerfully developed; and finally, the pelvic extremities relatively short, and not especially strong. Chamaa fasciata has very little affinity with this bird, so far as is indicated by external features and characters; and these are as much a part of its anatomy as are brain, viscera, or skull. The form of the plucked body in Salpinctes obsoletus is substantially repeated in Campylorhynchus brunneicapillus.

To sum up a little, then, as far as we have gone, and spreading out before us all our specimens of plucked birds now under consideration, carefully reweighing everything that has been set forth in the foregoing paragraphs, - then by a system of elimination, putting first aside the species having the greatest number of different characters, then the next one most evidently unlike our Chamaa, we find at last that we are compelled to decide in favor of a Psaltriparus as having the majority of characters in its external parts that approach the subject of our present memoir.

Turning for the moment to such foreign forms as Agithaliscus erythrocephaluts, Parus nepalensis, and Parus xanthogenys from the northwestern Himalayas, we find some interesting comparative points in them; for in the first-named species the general form of the plucked bird quite nearly resembles Chamea and the Bush-Tits of the genus Psaltriparus, in that its pterylography is very much the same; while the shape of the head, the shortish neck, and the lengthening of the pelvic limbs, though the latter is not so striking, all point to a parine structure, which approaches our Wren-Tit. 
This, however, does not apply to the two last-mentioned species, for in them these characters are far more like what we find in some of our typical Titmice, more especially such species as Parus gambeli or Parus atricapillus and its varicties.

I would also especially note that the shape of the bill in $A$. erythrocephalus more nearly approaches that part of the anatomy in Chamea than any other bird which I have compared with it, or which is supposed to bear any relationship with it. Let us next cut down upon some of the internal structures, and see what they seem to point to, in the way of affinities.

The lower larynx or syrinx in Chamea, both in structure and its musculature, seems to depart in no way whatever from its constitution in the smaller passerine birds generally. I have examined it in a number of species, including Accentor and the Paride.

The tongue, agreeing in its principal features with the tongue in true passerine birds, has, nevertheless, its extremity in Chamea bluntly truncated square across, and this margin finished off with a fringe of fine fimbriations. This is the case in most of the Tits, while in the Wrens (Salpinctes) the extremity of the tongue seems to be simply pointed, and in Accentor it is distinctly once notched in the middle line, with the bifurcations showing a tendency to fringe.

As usual in Passeres the left carotid artery is the only one present, not only in our subject, but in all others examined.

Upon examining the intestinal tract, we find the pair of small cœeca present in all the species under consideration, and Chamea agrees with both Wrens and Tits in possessing a wonderfully small gizzard. And in these birds the organ consists of a strong, firm internal corneous coat, overlaid by a thin and delicate muscular one which readily peels off, leaving the complete corrugated cast of the dense internal layer. This is the case also in the Himalayan Tits referred to above. Accentor modularis, on the other hand, has a conspicuously large gizzard of very different structure; for although it has a small corneous internal coat, this latter is covered by a thick and strong muscular layer, and upon opening it $\mathrm{I}$ find numerous pieces of hard, flinty gravel (as large as No. 8 shot) mixed with seeds and insects. Measuring the greatest median longitudinal line of the plucked head of a specimen of Chamaea, we find it to be equal 
to $3.2 \mathrm{cms}$., while the greatest diameter of its stomach in any direction is equal to $1.2 \mathrm{cms}$. Now the same measurements for the following species are:-

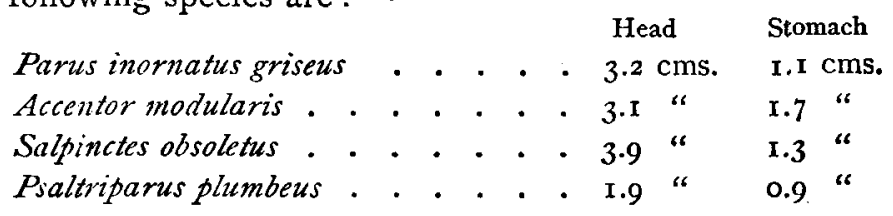

Further, I would add that the corneous layer of the gizzard in Accentor is much thinner than we find it in the Wrens and Tits, while the external form of the organ is entirely different.

Having carefully examined the myology of the limbs in Chamae and compared it with the corresponding structures in Tits, Wrens, Warblers, and the Accentor and others supposed to be more or less nearly related to our subject, I find no essential differences that will aid us in determining affinities. In all these forms, so far as I have been enabled to discover, the origin and insertion of the patagial muscles of the arm and the thigh muscles are essentially passerine.

With these investigations of the "soft parts" of Chamaa and its supposed affines before us, we will next pass to a comparative consideration of its skeleton.

\section{Of the Osteology.}

The Skull. - A great many of our smaller and ordinary passerine birds, such as the Wrens, Warblers, and some few others, have the superior osseous mandible, and the large subelliptical narial aperture on either side of it, constructed very much upon the same plan. The culmen is more or less curved gradually from frontal region to apex; the lateral edges are cultrate; and there is never any bony septum nasi, while it is entirely open on the under side between the delicate anterior limbs of the palatines. Seen upon side view, this pattern of the upper bony beak is well shown in Chamaa or in Psaltriparis or in Regulus (Figs. I, 3, and 4), while, though the plan remains identically the same, the form is somewhat altered by the lengthening of the beak in such Wrens as Salpinctes (Fig. 7), Thyrothorus b. spilurus, and the Cañon Wren (Catherpes). It is seen again in the Warblers, where recognizable differences of form obtain to an extent in this part of the skull sufficient to 
allow us to distinguish between the genera in some cases - not always an easy matter. For instance, in the numerous skulls of Warblers before me, the superior osseous mandible of Dendreca astiva is markedly more like Chamea in this particular than is the Prothonotary (Protonotaria), and Mniotilta more than either.

In this particular Psaltriparus plumbeus (Fig. 3) is most like Chamea; Accentor agrees better with some of our Mniotiltida; while a departure becomes evident as we pass to certain Titmice.
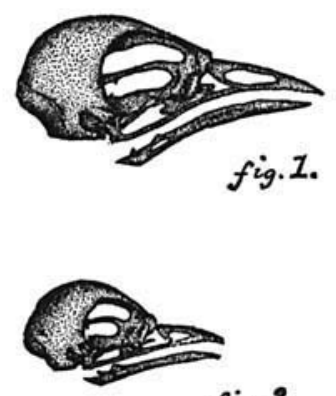

figns.

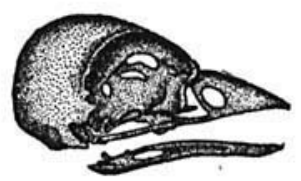

$$
\text { fig. } 5 \text {. }
$$

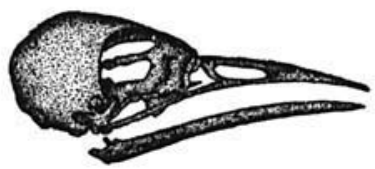

fig. $\%$
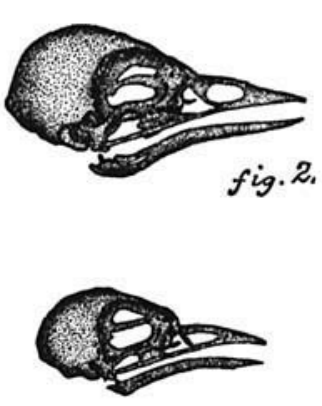

fig. 4 .

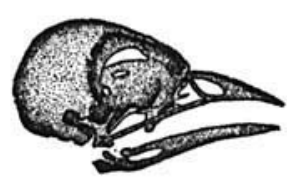

fig. 6 .

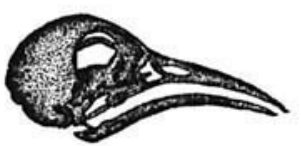

fig. 8.

Figure 1. - Chamaa fasciata.

Figure 2. - Accentor modularis.

Figure 3.-Psaltriparus plumbeus.

Figure 4. - Regulus satrapa.

Figure 5. - Parus [Lophophanes] inornatus griseus.

Figure 6. - Parus gambeli.

Figure 7.- Salpinctes obsoletus.

Figure 8. - Certhia familiaris americana.

These figures are all right lateral views, and life size, by the author, from the specimens. 
This change begins to be apparent in the Chickadees, as in Parns gambeli, or in the skull of $P$. carolinensis of a specimen kindly presented me by $\mathrm{Mr}$. Coale, or in P. rufescens. It consists mainly in a decrease in the size of the openings of the nostrils, and a broadening of the culmenar bridge between them. And it is in such species as Parus inornatus (of the subgenus Lophophanes) that we find a vastly different state of affairs prevailing (Fig. 5), for in them the upper bony beak is shorter; less pointed anteriorly; broadly rounded from side to side for the entire length of the culmen; the narial apertures subcircular instead of subelliptical in outline; their superior arcs widely separated by the great width of the nasal processes of the premaxillary. Viewing the skull upon its superior aspect, we find that in Chamea the frontal region is extremely narrow between the upper edges of the orbits, more so, in comparison with its size, than in any other species we have under consideration, although the feature is common to them all. The cranial vault, the sides and back of the brain-case included, is a smooth and rounded dome in Chamea, the Wrens, Tits, Accentor, Regulus, and the rest, though it differs in the various genera and species, both in form and relative extent. For the size of the bird, Chameea has decidedly the largest cranial capacity, Psaltriparus about equalling it in proportion to its size, followed by Parus inornatus, then Regulus and the Chickadees; while the Wrens have a small brain-case as compared with their size, the same applying to Accentor and our Warblers. Lophopleanes has the posterior moiety of either orbital rim raised all round, a feature less marked in the Chickadees, while in Chamaa, the Bush-Tits, and Wrens it does not exist.

Some good distinguishing characters are also to be found on a lateral aspect of the skull, more especially in the condition of the interorbital septum. Barely any bone is to be found here at all in Chamea, it being absorbed by a large vacuity occupying the central part of the partition, separated only by a slender bar from the great coalesced openings above where issue the first pair of nerves. The optic foramina have also merged, and it consists now in a small, central, circular foramen completely surrounded by bone, at the median point of the upper arc of which the posterior end of the extremely delicate osseous rod which bounds the interorbital vacuity above is attached. Psal- 
[VoL. III.

triparus and most Wrens repeat this state of affairs almost exactly (compare Figs. 1, 3, and 7), while the septum is more nearly complete in Accentor, while in the Tits, more especially in Lophophanes, it comes very near being entirely so (Figs. 5 and 6). The zygoma is reduced to almost hair-like dimensions in all of these species, and the pars plana separating the orbital and rhinal spaces is comparatively large, tumorous, and of a quadrilateral form. Few characters, if any, are afforded by the posterior aspect of these skulls; in all this part of the cranium is rounded, quite smooth, always shows a supraoccipital promi: nence, but never the foramina on either side of it. So well known is the arrangement of the palatal osseous structures at the base of the skull in these ordinary passeres, that we will refrain from entering upon a detailed description of them here. The various parts, more particularly the palatines and maxillopalatines, differ to some extent in form in the several genera and species, but the arrangement remains essentially always the same. In all except Lophophanes the vomer is truncated anteriorly and variously notched, while in the excepted genus this bone shows a longitudinal median carination beneath, and is carried, in the specimen before me, to a point in front, as a whole it being shaped something like a diminutive oblanceolate leaf. Psaltriparus plumbeus has the bony structures at the base of the skull most like the corresponding ones in Chamaa; the Wrens and Chickadees seem to stand next in this regard, Accentor approaching the Mniotillide. Generally the narial ends of the maxillo-palatines are dilated into a small paddleshaped extremity, but in such a form as Regulus satrapa, however, no such enlargement exists, these processes each being long and very slender. Normally, they are not in contact either with each other or with any of the surrounding bones, and the vomer fuses with the palatines behind.

Of no very great strength in any of the species before me, the mandible in all is of a V-shape form, and differs principally in the size of the ramal vacuity. This is very large, relatively, in Chamea, Psaltriparus, Crested Tits, Chickadees, and some others, but notably diminished in size in most Wrens, where it may disappear altogether in some species.

Nothing worthy of special note characterizes the hyoidean apparatus, still less the intrinsic ossifications of either the eye or 
ear, their structure in these passerine types being well known, as is the fact that they seldom, if ever, offer us any important characters upon which to assist us in determining affinities.

Of the Remainder of the Axial Skeleton. - There are nineteen free vertebra between the skull and the pelvis in the spinal column of Chamea fasciata, and of these the first eleven are without ribs; the twelfth supports an exceedingly minute pair of rudimentary riblets; on the thirteenth these are longer; on the fourteenth they are fully developed, and have uncinate processes, but do not reach the sternum. The next five vertebra bear complete ribs, which connect with the sternum by hæmapophyses, and the thoracic ones all have long slender uncinate processes ; finally, there is a pair of "sacral ribs," without these latter, and whose hæmapophyses fail to reach the costal border on either side of the sternum.

Psaltriparus plumbeus agrees thus far, with respect to the vertebræ and ribs between skull and pelvis, with Chamea, and in both species the ribs in particular are very delicate structures; in the Bush-Tit being fully as much so as the ribs in a skeleton of the Rivoli Humming-bird (Eugenes fulgens), for which I am indebted to Mr. W. W. Price, of Tombstone, Arizona, who recently collected the specimen near that place, and presented it to me.

We also find, in this part of the spinal column, nineteen vertebræ in Accentor, but this species differs in this, that the hæmapophyses of the last dorsal vertebræ do not arrive at the costal borders of the sternum. This arrangement disagrees even with our North American Warblers (Compsothlypis, Dendroica, Protonotaria, and several others), and just at this moment I fail to recall to mind the sternum of any ordinary small passerine bird, that has, as have the two sterna of Accentor modularis before me, but four hamapophysial facets upon either costal border. I pointed out several years ago that in Otocoris the first pair, or one of the first pair, on either side, of the hæmapophyses, may fail to be present, and thus have a sternum with only four facets on either border, but in Accentor the missing facet is at the other end of the row. (Contributions to the Anatomy of Birds: Ostcology of Eremophila.)

The ultimate hæmapophyses in Accentor barely clear the costal borders of the sternum, and it is just possible that speci- 
mens may be found wherein their lower ends make their impress on the lateral sternal margins.

In a specimen of Parkman's Wren, which I collected here at Fort Wingate, New Mexico, in 1885 , there are also nineteen vertebræ in the column, between skuil and pelvis, with the same arrangement of the ribs as in Chamaa, but the twelfth vertebra, although the vertebral canal on either side of it is not closed, its pleurapophyses have not either been liberated as a pair of tiny ribs. This may prove to be the case in the majority of specimens of Chamea, but it is a matter of minor importance.

Among the Titmice (Parus) the same arrangement of the vertebra and their ribs obtains in this, the cervico-dorsal division of the column, and I am inclined to believe it to be characteristic of the majority of groups of oscine birds; Stumella, the Orioles, and some of the Crow-Blackbirds forming the principal exceptions. (See author's "The Skeleton in the Genus Sturnella," etc., Foumal of Anatony, London, April, 1888, Vol. XXII.) The comparison of this part of the skeleton then, in Chamea and its supposed affines, will not assist us much as a diagnosis of possible kinships among the various species under consideration, so we will next take a look at the pelvis.

Chamea has a pelvis fashioned after the general passerine type or model, and its sacrum, or the number of vertebræ that have co-ossified with it, seem to be twelve. This part is very large, as may be seen by examining it upon its ventral aspect, where a longitudinally disposed parial row of quadrilateral pitlets mark it for nearly its entire length. The obturator space is very large, while the hinder ends of the post-pubis and ischium on either side flare outwards a good deal. Proportionately, the ischiadic foramen is also big, and the obturator foramen completely surrounded by bone. Viewing this pelvis from above, we note that the præacetabular portion is narrow, and the ilia much concaved, the fore part of the internal margins of these bones not meeting here, but they gradually approach each other, and are finally in contact in the middle line, at a point just a little anterior to an imaginary line joining the acetabulæ. The post-acetabular space is broad, and of a quadrilateral outline. More or fewer pairs of interdiapophysial foramina are here seen, disposed as usual in a double row.

Of all the pelves before me, none approach, in detail, this pel- 
vis of Chamea, so closely as does the pelvis of Psaltriparus plumbeus, in which species this bone is quite the miniature of our subject's. One point, howcver, must be noted, and in the Psaltriparus the ilia do not conne quise in contact on the dorsal aspect, as we have stated above to be the case in Cilamea.

Passing to the Crested Tits (Loplophlanes), the pelvis still bears the same general features, but in it the internal margins of the ilia, opposite the acetabulæ, are yet further separated, and the sacrum here upon the dorsal aspect thoroughly exposed, in consequence, for its entire length.

Chickadees and Wrens are in the same case, their pelves agreeing very well with the others described, and with the sacrum well in sight along its entire dorsal aspect, the ilia not meeting each other in any part of that locality.

Accentor has a very different pelvis from this; and it agrees best with that bone in some of our larger Mniotiltidce, with a trace of the Sparrow in it, and belongs to a bird quite thoroughly removed from Chamaa.

Counting the free caudal vertebree in our subject, I find there are six of them, not including the large pygostylc. This latter bone has here rather a peculiar shape, its superior laminar portion showing near its centre an area where the bone is much thinner than at the edges; while below it is somewhat spread out, after the fashion of the Pici, only in a far less degree.

Six plus a pygostyle is also the normal complement in $P_{\text {sal }}$ triparis and all other Tits examined, as well as in the Wrens, and in Accentor, and finally in such species as Polioptila plambea, Regulus, and Protonotaria citrea. Let us next take a glance at the bones of the shoulder girdie in these several groups of birds; and first, in Chamea, we find the os furcula to assume the broad and deep U-shape pattern, its limbs being recluced to almost capillary dimensions, with a mere apolosy below for a hypocleidium, while the coracoidal ends of the limbs are comparatively very much expanded. A scapula has a long, narrow, thin blade, the posterior third of which is turned considerably outwards, and its apcx carried to a fine point. Most interesting, however, of all three is a coracoid, which here attains to a wonderful length, the bone being not a little longer than the greatest longitudinal diameter of the body of the sternum (not including the manubrium in the measurement). Its shaft is subcylindrical 
and straight, with its sternal end only moderately expanded, as is the other extremity of the bone, only moderately tuberous. When articulated in situ, these bones show no marked departures from the corresponding arrangement in all ordinary oscines. The Bush-Tits (Psaliripanus) have the bones of the shoulder girdle in all respects very similar to those just described for Cliamea, not omitting the unusual length of the coracoids, which here lack but little of being fully as long as the entire sternum.

In Lophophancs the hypocleidium of the os furcula is inclined to be slightly more prominent ; but beyond this minor difference, little change is to be discovered in the elements of this pectoral arch, beyond what has been given above.

Troglodytes among the Wrens may have the furcular hypocleidium still more conspicuous, and this also applies to the genus Salpinctes. Os furcula among these latter birds still retains its frail structure, a broad $U$ in form, gently curved backwards for its inferior moiety, which curvature begins almost imperceptibly near its middlc.

When we get among the skeletons of the Warblers (Mniotiltidx), little change is to be found in the shoulder girdle; but with them the hypocleidium of the fourchette is always of good size, as it is in Accentor modularis.

Chamea fasciata has a stcrnum of the well-known passerine pattern. It is peculiar, however, in that it is strikingly flat, there being but little concavity apparent upon its thoracic aspect. Its outer xiphoidal processcs are wonderfully slender, and the midportion very broad behind, which latter fact renders the outline of the body quite square. Its keel is shallow and weak. Indeed, the entire bone in this bird is a very delicate one, as compared with the size of its owner. Psaltriparus plumbcas has a sternum the very counterpart of the bone in Chamaa, only in miniature. Its body, however, is more concaved, and the mid-xiphoilal margin not so long comparatively. Its pattern is considerably changed in the Crested Tits (Lophophanes), where the body is far more oblong rather than square; the midxiphoidal margin much more contracted ; the "notching," comparativcly speaking, not so profound as in the Bush-Tits; the keel more ample; and the costal processes and manubrium stron ly developed. The lattor shows a deep carination beneath, which is scarcely at all evident in Chamea. Troglodytinee, 
although they have, as a rule, a sternum in each species with a style to it of their own, yet by the slightest modification it could be easily made to assume the pattern of the bone, as we find it among most North American Parine. For example, how much the bone is alike in two such species as Salpinctes obsoletus and Panus inomatus! Again, take three such sterna as are offered us in the skeletons of Protonotaria citrea, Accentor modularis, and Icteria virens, and how marvellously close is the similarity, even to the most insignificant details (barring the one less facet on either costal border, in the case of the second-named species); and if guided alone by their form, how difficult it would be to distinguish them without any other assistance! And yet, were the sternum of Psaltripanus plumbeus brought up to the size of the sternum in the Prothonotary Warbler, we would have no difficulty in such a matter, notwithstanding the fact that the general pattern in both is the same; and how extraordinary is the gentle gradation in form between two such species, in this part of their skeletons, with respect to species of intermediate affinity!

On the Appendicular Skeleton: the Pectoral Limb.-As is usually the case, the several bones of the limbs of these small passerine birds offer us but a slender list of distinguishing characters, in any way pointing to the affinities of the species compared. In Chamaa the bones of both extremities appear to be completely non-pneumatic, whereas in such a Tit as the Parus inornatus both the humerus and femur have air admitted to their shafts; and I am not certain but that the long bones of the antibrachium and leg are in the same case. Other Tits also have the arm and thigh bones pneumatic. The humerus in our subject is characterized by having a notably straight shaft, and for its brevity, as compared with the size of its owner. Its head and distal extremity, however, are in harmonious proportion with its length; while the small glenoid cavity of the shoulder girdle, intended for its articulation, is re-inforced by a fair-sized os humero scapulare, in which it agrees with other species and genera before me.

Both bones of the antibrachium, the radius and ulna, are likewise very short and very straight. This may be best appreciated by stating the fact that the radius in Psaltriparus plumbeus comes within a hair's breadth of being fully as long as that bone 
in the forearm of Clamaea, yet see the difference in the size of the skulls of these two birds in Figures $I$ and 3. Another way we have of contrasting such a matter is by the fact that the tibio-tarsus in Chamaa is very nearly three times the length of its radius, and the tarso-metatarsus is nearly double its length. Nothing specially noteworthy is met with in the skeleton of the pinion in our subject. Measured from the head of the carpometacarpus to tip of the most clistal phalanx, this division of the skeleton of the pectoral limb is nearly as long as the ulna. The Bush-Tits have these parts quite in proportion with the size of their bodies, but otherwise the form of the bones is pretty much the same.

Parus inornatus (Lophophanes) presents some peculiarities in the skeleton of its antibrachium and pinion, for the outer surface of the proximal third of the shaft of the radius always develops a scale-like projecting ledge. While the proximal phalanx of the index digit is flat and smooth upon its radial side, it is deeply excavated for the entire length of its anconal aspect; and finally, the slender middle digit extends for an unusual distance below the main shaft of the carpo-metacarpus (or index digit), allowing its rather large and single phalanx to descend to a point considerably below the middle of the hinder margin of the proximal phalangeal joint of the index finger, whereas, as we know, in most bircls it is stowed away in the recess at the upper third of this joint. Chamaa also reveals its parine affinities in this particular, for the skeleton of its pinion is constituted pretty much on the same plan.

Wrens have their arm-bones a good deal like we find them in the Parine, but here a noticeable flattening of the radius always seems to be present, and characterizing the proximal moiety of the shaft of the bone.

Accentor modularis offers us nothing peculiar in its skeletal wing structure worthy of especial note; it is formed upon a strictly passerine type.

The Pelvic Limb. - So far as the characters of the bones of this limb themselves are concerned, they present so few strong differential ones to assist us in determining affinities that we might with great propriety pass them by at this point, but still a word in regard to other matters concerning them will not be out of place. In Chamaa all the long bones of the pelvic limb 
are conspicuous for their slenderness, and in the case of the tibio-tarsus and tarso-metatarsus, for their unusual length; the femur in this species is relatively very short, and is convexed forwards near its middle. To show some of these discrepancies in length we have but to present a few measurements :-

TABLE.

(Metric Measure.)

\begin{tabular}{|c|c|c|c|c|}
\hline SPECIES. & $\begin{array}{c}\text { LeNGTH of } \\
\text { SKULL. }\end{array}$ & Femur. & $\begin{array}{l}\text { Tinin- } \\
\text { TARsts. }\end{array}$ & $\begin{array}{l}\text { TARSO-META- } \\
\text { TARSUS. }\end{array}$ \\
\hline Chancea fasciata. . . . . & $3.1 \mathrm{cms}$. & I. $6 \mathrm{cms}$. & $3.3 \mathrm{cms}$. & $2.5 \mathrm{cms}$. \\
\hline Parus inornatus griseus. . & $3.1 " 4$ & 1.7 “ & $2.8 ،$ & 2.16 \\
\hline Salpinctes obsoletus. . . . . & $3.8 ،$ & 1.7 “ & 2.7 “ & I.9 " \\
\hline Psaltriparus plumbeus . . . & I.8 “ & I.I “ & 2.1 “ & 1.56 \\
\hline
\end{tabular}

As in the vast majority of all true oscines, - indeed I cannot recall an exception to the rule, - Chamae possesses a small patella at the front of its knee-joint embedded in the usual tendon. With respect to the tibio-tarsus, its cnemial crest is seen to rise well above the articular surface of the summit of the bone; and both its pro- and ectocnemial processes are well-developed. Distally the condyles are very prominent anteriorly, their outer peripheries being nearly exactly alike in outline, and of a uniform shape.

The shaft of this bone is wonderfully straight and of nearly the same calibre from one end to the other. Its associate in the leg, the fibula, is of very diminutive proportions, freely attached, and ossifies for only a short distance below its ridge for articulation on the shaft of the tibio-tarsus. Tarso-metatarsus also has a straight shaft, for the most part flattened in front and rather sharpened behind. The hypotarsus is comparatively prominent, and shows both grooves and canals perforated for the passage of tendons. At its extremity, the mid-trochlea is seen to be situated the lowest upon the shaft, and all three of these projections are very much in the same plane, or the one, approximately speaking, in which the anterior flat surface of the shaft may be said to lie. 
The "accessory metatarsal" is comparatively large as compared with the associated parts and supports a strong basal joint for the hallux digit. This is also the case in Salpinctes, another species which spends much of its time on the ground.

The arrangement of the joints of the toes, 2, 3, 4, and 5, for hallux to fourth toe respectively, is strictly passerine and presents nothing worthy of especial remark.

Aside from what $\mathrm{I}$ have pointed out then in the last few paragraphs touching upon the pelvic limb, the ornithotomist may be well assured that no vantage is to be gained, so far as the elucidation of affinities go, by entering upon a detailed comparison of the several characteristics presented in these bones of the supposed affines of Chamaa, for such characters are not of a nature of sufficient import to be brought into the discussion with any telling results, and the attempt to utilize such other insignificant differences as I have intentionally passed over, would simply be a profitless task.

In passing, I would say here that I have carefully compared in the present connection the skeleton in Lophophanes with a skeleton of Perisoreus c. capitalis, and find the latter to be essentially a garruline bird in so far as its osteology goes, and very easily distinguished from any Tit in our avifauna. It was Coues who said of our Paridee that, "really they are hard to distinguish, technically, from Jays ; but all our Jays are much over seven inches long." 1 The resemblance, aside from the question of size, and to a lesser extent, of color, in the case of Perisoreus and Lophophanes, is brought to mind by the agreement in the case of the corresponding morphological cletails exemplified by the majority of the external characters. It is immediately dispelled by a comparison of the skeleton in the two genera in question; though there may, however, be some remote affinity here.

In that Chamea lays plain greenish blue eggs, of course means something; especially as all our Wrens and Tits, as a rule, lay white eggs that are more or less spotted. Such a single character, however, often persists in a species, being carried down from the original ancestral stock, and to it no unjust weight must be attached. Then, too, it must be remembered that Chamea being related to the Wrens, and these latter surely

${ }^{1}$ Key to North American Birds, 2d ed, p. 263. 
being related to the Mimince, in that subfamily we find such a form as Galeosioptes carolinensis, which not only lays greenish blue eggs, but also sometimes has the tarsal scutella obsolete (it being generally so in Chamea). This and other minor points present themselves which will keep the fact before our minds that originally all these forms came from the same stock, and in the divergence which has subsequently taken place, in time, species have been created that are now remotely affined, as are such forms as Galeoscoptes carolinensis and Chamaa fasciata. Still Darwin has shown how such characters as I have mentioned above may be retained by the now more distantly related forms, and be transmitted by them.

So far then as the color of its eggs are concerned, it, as a character, points to the troglodytine affinity of Chamaa, probably in the way I have indicated, as birds directly related to the Wrens, as we have just seen, lay greenish blue eggs, and we are thus not compelled to pass beyond the limits of the family lines to obtain a likely explanation of this fact. At the present time I do not recall any typical parine form which lays an unspotted blue egg.

Recently I have had the opportunity of examining both Campylorhynchus brunueicapillus and Auriparus flaviceps in the flesh, several specimens of each. The former has all the characters of a large Wren, more nearly related to the species associated in the genus Harporkynchus than are any of our smaller Wrens; while the latter, notwithstanding its peculiar coloration, and some other non-strictly external parine characters, has a skeleton essentially very much like that part of the anatomy in Psaltriparus and its allies.

Before recapitulating the skeletal characters for comparison, of a number of the species we have been examining in the present connection, I would again lay stress upon the fact that in so far as its topographical anatomy and characters are concerned, Chamea shows a far closer kinship with Psaltriparus than it does with any of our typical North American Wrens. In the matter of coloration simply, its predominating shades of brown seem to point Wren-wards; still we must remember here that in the case of the inland form of Chamaea (C.f. henshawi) the prevailing tints of the plumage are of a grayish ash, which Coues admits is "about the color of a Lophophanes." 1 Already 
I have said, that when the species now grouped in the genus Cinnicerthia come to be anatomically examined and carefully compared, they may show quite as much of the Tit in their organization as they do of the Wren. Indeed, they may stand directly between these two groups of birds, and the new Cinnicerthia described by Mr. Sharpe in the Catalogue of the British Museum, may prove to have far more of the Wren in it than has Cinnicerthia unibrunnea; or still more than C. uninufa. Our hard and fast lines in systematic classification are a little binding sometimes, and do not strictly define the delicate relationships existing among such forms as go to make up the class Aves.

\section{Conclusions.}

It is only when one comes to investigate the morphology, in its entirety, of the smaller passerine birds, that it can in any way be appreciated how thickly the twigs stand upon that branch of the genealogical avian tree. As they have forked and split up, and been derived from each other, so have the bird forms which now represent this branching growth, become distinct in their thousand and one species, and in each we may look for inherited characters that likely they assumed and appropriated from a variety of ancestors at various stages of their derivation and offshooting. Thus it is that we may come across a species of bird wherein the main trend of its morphology and organization is indubitably stamped with all the characters of the stock-branch, or that off-shoot where all those of its kind could be designated as clearly differentiated Passeres for instance, and yet it will show in different degrecs tinctures in its make-up that have been borrowed by its economy from the earlier branchings that preceded it.

We may have a passerine bird presented to us, to offer an hypothetical case, which, to all intents and purposes, is in its entirety a representative of the great group which we have defined by that name. It may be the most fixed species of its genus, and yet when we come to study its structure in all its details, how puzzlingly do the anatomical evidences of its affinity crop up. So dilute may have some of the blood of remotely affined tribes run into itself that it lies quite beyond the power 
of man to detect them, much less accurately state from whence they were derived. Then again, other characters present themselves which almost stand boldly out in their significance, and point but in one direction to the kindred stock responsible for them. Who is the one among us who can truly tell just exactly how much of Steatornis is Owl, or how much typical picine stock there is in Yunx? And such problems are even still harder to solve where the affines are thickly clustered, and such are the difficulties we meet with when one attempts to unravel the ancestry of such a species as Chamea fasciata.

Apart from its larger size, there is no question, after we have stripped specimens of all our United States Wrens and Titmice of their feathers, but that the general form of a Chamea is more like a Bush-Tit (Psaltriparus) than it is like any of the rest of them, and this resemblance is real. Not to pass beyond the avifauna of this country then, we have shown in the text how this resemblance is again supported by the anatomy of the "soft parts,"-greater preponderance of characters of these birds being found in Chamaa over its troglydytine ones. Coming to the skeleton, a part of the organization from which we have the right to draw upon for our conclusions, it being one of the most reliable systems, and one which long retains the indices of a vertebrate's affinities, we see, at least, something to assist us in pronouncing upon the kinship of Chamaa.

Surely no one could be made to believe that Chamea bears any close osteological resemblance to such a form as Catherpes $m$. conspersus. The short-faced, semi-rotund skull of the former, with its maxillo-palatines having their free mesial ends large, thin, flat, and squarish; with its palatines having rounded posterior-external angles, and with a differently formed vomer and mandible ; - certainly all this is quite at variance with the longfaced, strikingly flattened skull of the latter, with its maxillopalatines having their free mesial ends narrow, thin, and posteriorly produced; with its palatines having their posteroexternal angles produced and angular; and finally, with the differences in the vomer and mandible spoken of in the text of this monograph. These cranial differences, as we now know, are also supported by others in the trunk skeleton in the two species in question. Withdrawing, then, such a form as Catherpes $m$. conspersus, we find it followed by its evident allies in our 
fauna, the representatives of the genera Troglodytes, Salpinctes, Campylorhynchus, and others, although many of these show, perhaps, a somewhat closer affinity with Chamea than does Catherpes, but behind that fact it still remains clear that they are all Wrens in every sense of the word. Campylorhynchus, which by some has been supposed to be nearer Chamea, has a typical Wren's skull, and one reminding us not very much of the WrenTit.

One of the best cranial characters distinguishing these birds is to be found in the form assumed by the free mesial extremities of the maxillo-palatines; these differences I have already clearly defined above, and they are constant; and furthermore, these parts are alike in Chamaa and Psaltriparus, and differ from all the Wrens. The sternum offers us hardly a distinguishing character, but it would seem that the fact whether or no the ilia meet the sacral crista mesially should have its weight, and here Campylorhynchus is the only Wren that agrees with Chamcea in that particular, whereas the Bush-Tits practically add this feature to the other list of characters that force us to believe them to be more nearly related to Chamaa than any other species of bird at present known to our avifauna.

As I have already stated, judging from topographical anatomical characters alone, I am strongly inclined to think that Chamea fasciata may be related to the Cinnicerthia unirufa, of Colombia, but I am also convinced that that latter species is not a whit nearer in its affinity to such a Wren as is Catherpes m. conspcrsus, than is Chamea.

Whether Cinnicerthia has any parine affinity, and just how much, is a question, I believe, that still remains for the morphologist to decide. 